\title{
Ethnocentrism, Cultural Traits and Identity Negotiations of Japanese EFL learners
}

\author{
Nooshin Goharimehr \\ Department of Education- Graduate School of Human Sciences- Osaka University- Japan \\ ngohari2014@gmai1.com
}

\begin{abstract}
In contrast with learning English as a second language (ESL) in English speaking countries, learner identities in an EFL setting may be impacted by various contextual factors such as the learning environment's unique sociocultural characteristics, ideologies and social values. Drawing on poststructuralism, the present research attempts to understand how Japanese learners of English build their own subjectivities in connection to their cultural traits, ethnic identity and other socio-psychological factors affecting their learning and speaking practices. This is a partial report on a research about Identity, Self and EFL learning which was conducted among 70 undergraduate university students in Japan. The research suggested that ethnic identity can interfere with the development of L2 identity through identity resistance. The cultural and sociolinguistic differences between the native and target languages can impact the language learning practices and identity construction in EFL learners.
\end{abstract}

Keywords: EFL learners, Ethnocentrism, Cultural Traits.

\section{Introduction}

English learning and usage is spreading rapidly around the world. Globalization, which is the process of international integration and world-wide convergence in education and other sectors is transforming the environment in which English is learned as a second language (ESL) or foreign language (EFL) (Held et al., 1999). It's important to recognize the impact of economic and cultural globalization on the globalization of language, and specifically the extended role of English as lingua franca (Crystal, 2003). English language education in Japan has become more indispensable because of globalization. As globalization continues, so shall the negotiation of identity and the place of English in Japan.

In the Japanese EFL (JEFL) context, the Ministry of Education, Culture, Sports, Science and Technology (MEXT) has been setting the goal of mastering English language skills for Japanese students to become competent members of "global" society. Although, Japanese students study English for quite a long time, in terms of communicative skills, there seems to be a lack of progress in different levels of academia. Many educators consider silence and lack of interaction in English classrooms, which is often interpreted as lack of motivation, a reason for poor communicative skills. It has also been argued that Japanese cultural identity or different communicative norms might interfere with risk taking and speaking practices which is a prerequisite for English learning.

Accordingly, the investigation of learner identity in Japan will significantly contribute to the field as there is little qualitative academic research into the reasons why Japanese students are particularly identified as reluctant to speak in a second language even those who possess high reading and writing proficiency. Furthermore, Scholars in the field of additional language acquisition have been struggling to determine the relationship between the language learner and the social world to conceptualize a comprehensive theory of social identity which integrates the 
language learner and the language learning context (Norton, 2000). If we consider language as the representation of identity, then we can argue that there is a connection between ethnic identity and one's view of a foreign language. The way L2 learners view the target language and identify with it determines their learning and L2 identity construction. Hence in this paper, I will investigate how the EFL students' ethnic identity and the cultural background impact their L2 identity negotiation and language learning practices.

\section{Identity and foreign language learning}

Weinreich (1986, pp. 39-72) defines a person's identity as "the totality of one's self-construal, in which how one construes oneself in the present expresses the continuity between how one construes oneself as one was in the past and how one construes oneself as one aspires to be in the future"; He further defines ethnic identity as " that part of the totality of one's self-construal made up of those dimensions that express the continuity between one's construal of past ancestry and one's future aspirations in relation to ethnicity".

Language is the most prominent demonstration of one's identity and consequently learning a foreign language leads to adopting a new identity. Norton (2013) conceptualizes identity of the language learner (L2 identity) as pertaining to "the ways in which language learners understand their relationship to the socio-cultural contexts, how that relationship is constructed across time and space, and how the learner understands their reflections for the past and possibilities for the future" (p.45). Accordingly, identity should be considered as socially situated and constructed, dynamic, contradictory, and continuously changing across time and place (Block, 2007; Norton, 2006). Therefore, the native and target cultures can play important roles in shaping the identities.

Moreover, identity is an important factor in additional language learning because linguistic patterns signal social and individual identity, and people's conscious awareness of their personal identities appear in language use. Poststructuralists depict the individual as diverse and dynamic, hence identity is a site of struggle in which a person takes on different subjectivities structured by relations of power in a variety of social sites. These subject positions such as mother, teacher, student, and other positions could be in conflict with others (Norton, 2000). Consequently, identity construction is a complicated process or as Robertson (1998) put it, "condensed in an intersection of a myriad of complex sociological factors within a historical moment" (p. 455). Therefore, the process of identity construction and negotiation deals with the life experiences individuals go through in a given social setting in which the interaction of identities would have not been the same if the context were different.

\section{Ethnic identity and EFL}

There has been much effort to boost the status of English teaching and learning in Japan, however, there are still shortcomings when it comes to the communicative skills and speaking ability of EFL learners. There are various factors affecting teaching and learning which are rooted in sociocultural aspects of the country and linguistic differences between Japanese and English. This issue is inherent in the native cultural values and signifies the importance of understanding the learning culture and social factors behind the learning process. In a larger scale, how English is viewed as a foreign language and its status in the social context of Japan can contribute to the teachers, policy makers and students' educational approaches toward learning. Sugimoto (1997) claims that there is a prevailing dichotomous view in the Japanese society which regards the world as split into two spheres, Japan and the West. The cultural nationalism assumes that the moral, spiritual and cultural life of the Japanese people should not be affected negatively by foreign 
values regardless of their impact on Japan's material way of living. This view of cultural nationalism develops into the dichotomous view of language; meaning that Japanese culture and language is considered in opposition to language and culture of English speaking countries.

Schneer (2007) found that the images and cultural explanations in high school textbooks endorsed by MEXT represent the cultural aspects of the native and target languages from a standpoint of opposition. Therefore, the more Japanese master English and internalize the cultural traits and ideas associated with it, the more they lose their cultural values or in another word "Japaneseness" as English is considered as a tool that transmits the Western values and beliefs (Fujiwara 2004). Regarding this linguistic cultural conflict which is still relatively present in some Japanese educational settings, it can be expected that Japanese ethnocentric beliefs and values may influence English language learning. Some studies found that ethnocentrism played a negative role in English language learning and performance resulting in low English proficiency of Japanese students which was interpreted as the socio-cultural product (Yashima, 2000, Doerr, N. M., \& Lee, k., 2013). Turnbull's (2017) research showed that Japanese participants in his study identified the Japanese language as an element of their national identity and that removing Japanese language from EFL classes could result in negative ideologies toward English learning.

Regarding the issues around identity construction and resistance in ESL contexts, Morita (2004) investigated how Japanese L2 learners negotiated their membership and identities in new academic communities in Canada. Japanese students tended to position themselves as being less competent than other local students due to the lack of understanding of reading materials, lectures, and classroom participation rituals. Furthermore, some participants constructed these identities with regards to the ways other peers perceived them while others began to negotiate their identities by applying strategies such as self-study or asking instructors questions. Liu's (2002) research on Chinese students indicated that ESL/EFL teachers should be aware of the learners' cultural differences and the various challenges and struggles they experience attempting to develop new identities as L2 learners and becoming members in communities of practice. Hence, in order to improve learning and teaching practices in classrooms, as English teachers, it is important for us to understand the cultural predispositions and differences that have direct implications for English learner identity and learning.

\section{Research questions}

4.1. Are there any conflicts between students' cultural identity and L2 identity?

4.2. What are the affective and contextual barriers to EFL learning perceived by Japanese students?

\section{Research method}

This paper is a partial report on the data obtained from a bigger research conducted on motivation, self and identity of EFL learners in a Japanese context. The study applied a qualitative approach to the data obtained through participants' responses to an online questionnaire. The students' comments were analyzed by thematic content analysis.

\subsection{Data resources}

The participants of this study were 70 undergraduate students of six CALL Writing Classes and three integrated English speaking courses in a public university. The participants' information is presented in a table1 (see appendix 1).

\subsection{Data collection techniques}

This paper draws on the data obtained through an open-ended questionnaire. The open-ended questionnaire was designed to extract responses which both directly and indirectly served to answer the research questions and complement the previously conducted survey. This questionnaire consisted of 5 major questions with minor editions to suit two different courses 
under study. These questions addressed several variables such as: Learning goals, learning barriers, Positive and negative learning experiences, Anxiety and linguistic self-confidence, Identity changes, and Imagined communities of practice. In addition to these constructs, the students' detailed and spontaneous responses were sought to provide extra information on other variables pertaining to motivation and identity research. In this short paper, I will focus on the evidence from data regarding the interplay of variables pertaining to identity, cultural traits and English language learning.

\section{Data analysis and discussion}

A content analysis of responses to open-ended questions rendered several major themes which are categorized based on concepts of identity and motivation theories (See the appendix 2). This paper focuses on the themes and responses which are related to the research question regarding cultural conflict and identity resistance. According to the results, there was a trace of cultural resistance toward English learning or integrative motivation which is a desire to integrate with and identify with the target vulture community:

\section{Chiaki (f): "When I was in high school or junior high, it was ridiculous for students to pronounce English so seriously, and if one student tried to do so, everyone laughed. i hated it. I don't feel comfortable at any time when I speak in English. So I am not willing to speak in English. I usually speak English with a teacher of English class, or other students when a teacher directs to do it...I prefer less interactions because it is less stressed."}

Chiaki relates her experience of learning English in high school and her frustration to stand out among her peers for trying to learn and speak English seriously. This shows a sort of L2 identity resistance among Japanese students as well as the anxiety caused by avoiding conformity in a Japanese setting. Hence, Chiaki doesn't feel comfortable speaking English as this context limits her from creating her L2 identity. Moreover, the psychological effects of this situation has developed a fear of interaction even in the university classroom which offers more possibilities to practice English without facing peer pressure.

Furthermore, none of the participants in the study mentioned a desire to immigrate to a new country or live abroad permanently. Living abroad was only mentioned few times in the responses $(\mathrm{F}=4$, See table 2). This fact displays a tendency which is rooted in Japanese culture and strong ethnic identity. Living in a foreign country necessitates the ability to get closer to the target language identity and community. For Japanese students, going abroad is limited to attaining intercultural or academic experience and fulfilling their interest in learning about new things (cultures, people, ideas, etc.).

In terms of barriers to effective leaning and negative factors affecting the learners' identity construction, several participants expressed an anxiety caused by lack of opinions and inability to express themselves. This can be due to sociocultural background of Japanese students and the practice of silence. English and Japanese languages are different in many ways. Apart from linguistic differences, many of the difficulties that Japanese learners have with English are mostly caused by differences in communication styles and culture. Japanese language is associated with a respect for abstraction and indirect communication which can cause Japanese learners to struggle to find the best way to express themselves. As Kunihiro (1975) put it, "in Japan, language, communication through language, has not received the same emphasis as in the West. It has been considered poor policy to use words as a tool to express one's views, to persuade the other fellow or to establish any depth of understanding. Language as an instrument of debate or arguments is considered even more disagreeable and is accordingly avoided. Thus, in Japanese society, use of 
words becomes a sort of ritual, not often to be taken at face value. It is only one possible means of communication, not the means of communication as is often the case among English speakers" (p.97). The cultural differences are perceived and handled by some learners in both positive and negative ways:

Kaito (m): "I can think many ideas in my brain in Japanese, so I want to speak the ideas, but I can't compile them in English. I've experienced the situation so much. I want to change the situation in English classes."

Miwa (f): "In Japan, people do not say everything, so they cannot understand what they mean, but if we speak English, we have to express all of my opinion; so I can understand what I am thinking and how I am feeling. If I get only Japanese culture, I cannot imagine idea more."

For Miwa, the cultural context seems to be limiting her identity. She is well aware of the fact that to be able to improve her speaking, she needs to express her opinions. She thinks that Japanese don't express all their opinions so within her native language, she cannot imagine new ideas. However, she seems to have a positive attitude towards the new identity of an English speaker who is more straightforward and opinionated.

Masa (m) : “...I don't like English, because English is very difficult for me. I'm not good at and don't like remembering. Usually I don't want to use English, but I use

English when foreign people ask me to tell way. When I use English, I'm very uncomfortable because I can't talk what I want to talk. I learn English only to pass the exam. I can't image myself because I can't learn advanced English...."

Masa doesn't like English as he finds it difficult. Also he considers himself incompetent. For him, learning English mostly serves to passing exams. He cannot imagine his identity as an L2 speaker and he finds it difficult to express his thoughts and opinions. This lack of self-confidence and inability to freely express his identity in English has demotivated him in doing so.

Naoya (m): "My goal is to understand every article that is written in English.... when I speak English, I don't have the confidence to tell my thoughts and feelings."

Although Naoya has a clear goal to understand English articles, he doesn't feel confident in expressing himself in English either.

Taku (m): "When I speak English, I think hard the way to tell my opinion."

Rina (f): "I feel comfortable to speak English when I talk with my Japanese friends who are not so good at English ...I realize I have less opinions and knowledge than English speakers because sometimes I can't answer to questions asked by them."

Rina and Taku also feel incompetent in expressing their opinions. The anxiety and lack of confidence is evident in Rina's comment as she prefers to speak with low proficient English speakers to avoid tension. She realizes that she does not have much knowledge and opinion compared to English speakers and this might be a reason for her anxiety. As mentioned earlier, Saori also links her lack of confidence and motivation to inability to express her thoughts: 
Saori (m): "in English class and was made to explain my opinion again and again. I was hurt by experiencing sadness of not telling my opinion smoothly. Therefore I feel English little hard."

A better example would be the case of Momo which also shows how stressful expressing opinions can be for Japanese students:
Momo (f): "When I am asked my opinion, I often consider too seriously. I can't find good word for express my opinion and I fall silent. Sometime my conversation partner changes the question to yes-or-no question, and I feel relieved."

Hideo (m): "I can't communicate with people in English well. Learning English is useful and interesting, but I have no time to study more. I feel comfortable when I express my opinion in English class. English doesn't have the word of respectful, so it is difficult for me to speak with older people in English."

A communication difficulty rises for Hideo due to different sociolinguistic aspects of English and Japanese. The Japanese language encodes features such as social relationships and power rankings, while English does not have as many encodings. Therefore, understanding the cultural and psychological reasons behind students' speaking difficulties is crucial for English teachers to help them overcome communication barriers. However, the discrepancies between the two cultures and linguistic systems have also positive impacts on identity construction for some learners. In response to the question whether they felt any changes after learning English, Katsuo expressed a positive change which is being able to speak more frankly and directly:

\section{Chisako (f): "I can say my opinion clearly when I use English"}

Chisako feels a positive change which is the ability to express her opinion more clearly in English. This also shows the trace of identity changes as these learners communicate in English. Similarly, Miwa feels the need to shift her identity due to differences between English and Japanese communication styles:

Miwa (f): "Learning English is useful because most people in the world tend to speak English and we should communicate more people because of getting more inspiration.

I feel it when I talk with people who speak English and they get to understand my opinion. In Japan, people do not say everything, so they cannot understand what they mean, but if we speak English, we have to express all of my opinion."

Miwa understands well that she must change her identity position when she speaks English and become more expressive and straightforward. This awareness of identity change has helped her to overcome the communication challenges and adopt a new identity. It even shows some kind of preference in her toward her L2 identity as it provides her with better communication as opposed to Japanese.

\section{Conclusion}

In sum the analysis of participants' responses to the survey suggested that a major challenge for the Japanese EFL learners was negotiating their beliefs, cultural traits, competence, identities, and views toward the native and target languages so that they could participate and be recognized as a competent and legitimate members of a specific social, business, academic or international 
community of practice. The participants of this study had to overcome several barriers such as lack of linguistic self-confidence, shyness, anxiety of failure or making mistakes, a tendency toward perfectionism and an identity shift from Japanese to an L2 speaker. Some cultural traits of Japanese learning settings such as conformity and avoidance of standing out among peers limited them from developing their L2 identities which will not happen unless the learners express themselves freely and communicate in English.

We can conclude that an important factor behind the lack of students' speaking practices is the communicative differences which are rooted in the culture. These fixed behaviors or sociocultural identities may act as barriers to L2 identity construction. In order to learn a new language, a learner is supposed to adopt new ways of thinking and expression. English speaking practice requires the learner to be willing to express his opinions which is not an easy task for Japanese students who position their identities as shy, non-speakers and unable to express their opinions. This indicates the importance of understanding the learners' psychological, cultural and affective barriers in order to devise teaching methods which are motivating and engage learners in constructing new identities and hence improve their learning.

\section{References}

[1] D. Block, (2007). The rise of identity in SLA research, post Firth and Wagner (1997). Modern Language Journal, 91, 861-874. http://dx.doi.org/10.1111/ j.1540-4781.2007.00674.x

[2] D. Crystal, (2003). English as a global language. Cambridge: Cambridge University Press, 2nd ed. First ed., 1997.

[3] N. M. Doerr, and k. Lee, (2013). Constructing the heritage language learner: Knowledge, power, and new subjectivities. Boston, MA /Berlin, Germany: Walter de Gruyter, Inc.

[4] A. Egan-Robertson, (1998). Learning about culture, language, and power: Understanding relationships among personhood, literacy practices, and intertextuality. Journal of Literacy Research, 30(4), 449- 487.

[5] M. Fujiwara, (2004). Eigo ky iku no jy shi ga nihonjinno kyoyo wo sarani teika saseruniwa machigainai. [The emphasis on English education lowers Japaneseness and personal enrichment]. Nihon no ronten. Tokyo: Bungei Shunju.

[6] D. Held, et al. (1999). Global Transformations. Cambridge: Polity.Kunihoro, M. (1975). Indigenous barriers to communication. Japan Interpreter, 8(1), 96-108.

[7] B. Norton, (2000). Identity and language learning: Gender, ethnicity and educational change. Harlow, England: Longman/Pearson Education Limited.

[8] B. Norton, (2006). Identity: Second Language. In K. Brown (ed), Encyclopedia of Language and Linguistics, Second Edition: Elsevier TESOL Quarterly, 35(2), 307-322.

[9] B. Norton, (2013). Identity and language learning: Extending the conversation (2nd ed.). Bristol, UK: Multilingual Matters.

[10]D. Schneer, (2007). (Inter)nationalism and English textbooks endorsed by the Ministry of Education in Japan. TESOL Quarterly, 41(3), 600-607.

[11]Y. Sugimoto, (1997). The Japan phenomenon and the social sciences. In An introduction to Japanese society, ed. Y. Sugimoto. 1-36. Cambridge: Cambridge University Press.

[12]B. Turnbull, (2017). Learner perspectives on national identity and EFL education in Japan: Report of a questionnaire study. Journal of Asia TEFL, 14(2):211-227.

[13]P. Weinreich, (1986). The operationalization of identity theory in racial and ethnic relations. In J.Rex and D.Mason (eds). Theories of Race and Ethnic Relations. Cambridge: Cambridge University Press.

[14]T. Yashima, (2000). Orientations and motivations in foreign language learning: A study of Japanese college students. JACET Bulletin 31: 121-133. 


\section{Appendices}

Table1: The participants' characteristics: $1^{\text {st }}$ and $2^{\text {nd }}$ year undergraduate students, age: 18-22 years old - (PNT: Prefer not to answer)

\begin{tabular}{|c|c|c|}
\hline Pseudo Name & Gender & Field of study \\
\hline Akira & Male & Engineering science \\
\hline Takuya & Male & Engineering science \\
\hline Haruka & Female & Engineering Science \\
\hline Yuuki & Male & Electronics \\
\hline Hideo & Male & Engineering Science \\
\hline Masa & Male & Science Engineering \\
\hline Akita & Male & Engineering science \\
\hline Miharu & Female & Electronics and materials physics \\
\hline Fumiya & Male & PNA \\
\hline Naoki & Male & IT \\
\hline Kaito & Male & PNA \\
\hline Kota & Male & Physics \\
\hline Kenta & Male & Mathematics, Information Science \\
\hline Naomi & Female & Biological science \\
\hline Sakura & Female & Science, major in biology \\
\hline Kosuke & Male & PNA \\
\hline Kohei & Male & Physics \\
\hline Kazuto & Male & Chemistry \\
\hline Shoko & Female & Biology \\
\hline Akihiko & Male & law \\
\hline Miwa & Female & law \\
\hline Atsushi & Male & Japanese history \\
\hline Ichiro & Male & Law \\
\hline Isao & Male & Economics \\
\hline Rina & Female & International public policy (school of law) \\
\hline Hisaya & Male & Economics \\
\hline Hiroya & Male & Mathematics \\
\hline Maki & PNA & Biology \\
\hline Etsuji & Male & Mathematics \\
\hline Daisuke & Male & Physics \\
\hline Takami & Female & Science \\
\hline Chikao & Male & Chemistry, science \\
\hline Kenji & Male & Biology \\
\hline Katsuo & Male & Science \\
\hline Chisako & Female & Science \\
\hline Jinichi & Male & Physics \\
\hline Itaru & Male & Mathematics \\
\hline
\end{tabular}




\begin{tabular}{|c|c|c|}
\hline Matsuki & Male & Economics \\
\hline Chiaki & Female & Literary arts \\
\hline Motoki & Male & Economics \\
\hline Naoya & Male & Economics \\
\hline Nobuhiro & Male & Law \\
\hline Umeko & Female & Geography \\
\hline Yumi & Female & Engineering science \\
\hline Nanase & Female & Engineering science \\
\hline Ryohei & Male & Engineering science \\
\hline Rikiya & Male & Engineering Science \\
\hline Shinzo & Male & Engineering Science \\
\hline Tadashi & Male & Chemistry \\
\hline Takishi & Male & Electronics \\
\hline Tomoki & Male & Engineering science \\
\hline Taku & Male & Engineering science \\
\hline Tatsuya & Male & Engineering science \\
\hline Wataru & Male & Linguistics \\
\hline Saori & Female & Literature \\
\hline Yoshio & Male & PNA \\
\hline Miki & Female & Art History \\
\hline Akari & Female & PNA \\
\hline Maaya & Female & Sociology \\
\hline Fusa & Male & Consulting \\
\hline Reika & Female & Chinese \\
\hline Sakko & Male & Finance \\
\hline Ryoko & Female & Japan \\
\hline Noriko & Female & Law \\
\hline Nozomi & Female & Chinese \\
\hline Eisuke & Male & Engineering Science \\
\hline Sumika & Female & Foreign language \\
\hline Momo & Female & Mechanics \\
\hline Daigo & Male & Electronics \\
\hline Saya & Female & English \\
\hline
\end{tabular}


Table2: Thematic analysis of student responses to the motivation and identity survey

\begin{tabular}{|c|c|c|}
\hline Category & Theme & Freq \\
\hline \multirow{17}{*}{$\begin{array}{l}\text { 1. English language } \\
\text { learning } \\
\text { motivations( } \\
\text { self/imagined } \\
\text { identity) }\end{array}$} & Speaking to foreigners/intercultural communication & 59 \\
\hline & Access to information, knowledge and foreign ideas & 34 \\
\hline & Academic purposes and study abroad & 32 \\
\hline & Joining new communities & 23 \\
\hline & Expressing and conveying one's ideas in English, & 20 \\
\hline & Using English for work and business & 22 \\
\hline & More value, power and a better life & 14 \\
\hline & Mastering English as an ideal self & 14 \\
\hline & Traveling/Living abroad & 13 \\
\hline & English is interesting & 13 \\
\hline & Improving speaking and fluency & 11 \\
\hline & Guiding foreigners & 10 \\
\hline & Confidence improvement & 10 \\
\hline & International issues & 9 \\
\hline & Media: Movies, songs and video games & 7 \\
\hline & Learning English as a necessity or obligation & 6 \\
\hline & Passing exams & 2 \\
\hline \multirow{6}{*}{$\begin{array}{l}\text { 2. Change in Identity } \\
\text { / Self }\end{array}$} & Broadening of perspectives and personality improvement & 25 \\
\hline & Identity construction & 20 \\
\hline & No identity change & 19 \\
\hline & Confidence improvement & 10 \\
\hline & Becoming more expressive and straightforward & 6 \\
\hline & Improving Critical and logical thinking & 4 \\
\hline \multirow{3}{*}{$\begin{array}{l}\text { 3. Anxiety and self } \\
\text { confidence }\end{array}$} & lack of proficiency and self-confidence & 33 \\
\hline & Linguistic and cultural differences and Inability to express opinions & 25 \\
\hline & Teacher interaction is stressful & 2 \\
\hline \multirow[t]{3}{*}{ 4. Demotivation } & No interest in English & 12 \\
\hline & Past negative experiences & 6 \\
\hline & Lack of opportunity to speak English & 4 \\
\hline \multirow{7}{*}{$\begin{array}{l}\text { 5. } \begin{array}{l}\text { Community of } \\
\text { practice }\end{array} \\
\text { a }\end{array}$} & foreigners & 59 \\
\hline & Imagined communities of practice & 23 \\
\hline & No desire to join communities & 12 \\
\hline & English community & 8 \\
\hline & talking in class & 7 \\
\hline & Speaking English with friends & 7 \\
\hline & Speaking to foreigners rather than Japanese & 5 \\
\hline \multirow[t]{2}{*}{ 6. Classroom factors } & Interest in English class and technology assisted learning & 39 \\
\hline & Improving the English class and interactions & 34 \\
\hline
\end{tabular}

